\title{
ANALISIS CUSTOMER RELATION DENGAN KEPERCAYAAN PENGGUNA JASA KERETA API EXPRESS PADA PT. KERETA API INDONESIA (PERSERO) DI BANDAR LAMPUNG
}

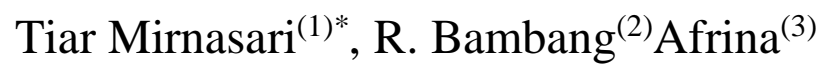 \\ ${ }^{(1)}$ Universitas Sang Bumi Ruwa Jurai \\ *email: tiarmirnasari2021@email.com
}

\begin{abstract}
Abstrak.
Penelitian ini bertujuan untuk menganalisis customer Relation dengan Kepercayaan Pengguna Jasa Kereta Api Express Pada PT. Kereta Api Indonesia (Persero) di Bandar Lampung. Jenis penelitian ini menggunakan kuantitatif deskriptif dengan teknik analisis menggunakan uji validasi produck moment, pengujian hipotesis menggunakan uji t. Metode pengumpulan data yang menggunakan jenis data primer dan data skunder dengan teknik pengumpulan data menggunakan observasi, wawancara, angket dan telaah kepustakaan. Jumlah sampel dalam penelitian ini adalah sebanyak 60 orang. Berdasarkan hasil penelitian dapat disimpulkan bahwa, hipotesis yang sebelumnya penulis ajukan yaitu "Ada pengaruh positif dari customer relation dengan kepercayaan pengguna jasa kereta api express pada PT. Kereta Api Indonesia (Persero) di Bandar Lampung.
\end{abstract}

Kata kunci: Customer Relation, Kepercayaan.

\begin{abstract}
.
This study aims to analyze the Customer Relationship with the Trustworthiness of the Express Train Service Users at PT. Kereta Api Indonesia (Persero) in Bandar Lampung. This type of research uses descriptive quantitative with the analysis technique using the product moment validation test, hypothesis testing using the t test. Data collection methods using primary data types and secondary data with data collection techniques using observation, interviews, questionnaires. and review the literature. The number of samples in this study were 60 people.Based on the results of the study, it can be concluded that, the hypothesis that the author previously proposed, namely "There is a positive effect of customer relations with the trust of express train service users in PT. Kereta Api Indonesia (Persero) in Bandar Lampung.
\end{abstract}

Keywords: Customer Relations, User Trust

\section{PENDAHULUAN}

Perkembangan ilmu pengetahuan manusia telah menunjukkan pada suatu keadaan yang menuju kepada peradaban manusia ke yang lebih baik. Dimana manusia akan selalu berusaha untuk menggerakkan kemampuannya dalam berfikir, berkehendak, dan berperasa. Dengan pikirannya manusia mendapatkan ilmu pengetahuan, dengan kehendaknya manusia mengarahkan perilakunya dan dengan perasaannya manusia dapat mencapai kesenangan, dengan demikian manusia adalah faktor yang dominan dalam mengisi pembangunan.

Manusia selain sebagai pelaku pembangunan juga merupakan sebagai sasaran dari pembangunan itu sendiri. Pembangunan di Indonesia begitu cepat karena adanya pengaruh dari faktor-faktor tuntutan pada masyarakat, tantangan alam, dan tehknologi yang semakin maju.

$$
\text { Customer relations (Puspa }
$$

Wildyaksanjani \& Dadang Sugiana, 


\section{EKOMBIS Sains}

2018)merupakan strategi baru untuk mengikat konsumen kepada suatu perusahaan. Tujuan customer relations tersebut adalah untuk menciptakan pelanggan yang loyal dan berkomitmen terhadap produk atau jasa yang dihasilkan oleh suatu perusahaan. Dalam sebuah perusahaan, melalui aktivitas customer relations akan berupaya semaksimal mungkin untuk mempertahankan loyalitas pelanggannya.

Menurut Ruslan (2008: 294), tujuan dari customer relations adalah mempertahankan pelanggan,menarik pelanggan baru, pemasaran produk atau layanan baru, kecepatan dalam penanganan keluhan, dan mengurangi biaya. Customer Relationship Management (Dewa et al., 2017) merupakan suatu proses menggali informasi yang dibutuhkan secara detail dan keseluruhan mengenai kebiasaan kebiasaan serta kebutuhan pelanggan untuk memaksimalkan loyalitas pelanggan.

Sektor jasa sebagai salah satu sektor penunjang yang memegang peranan penting dalam melaksanakan pembangunan. Sebagian dari sekian banyak jenis jasa yang berkembang dewasa ini, misalnya Transportasi (Angkutan umum darat, laut maupun (udara) Transportasi merupakan kegiatan pemindahan barang dan penumpang dari suatu tempat ketempat lain yang mempunyai fungsi untuk udara). Transportasi merupakan kegiatan pemindahan barang dan penumpang dari suatu tempat ketempat lain yang mempunyai fungsi untuk mengangkut penumpang dan barang dari suatu tempat ketempat yang lain. Dalam rangka menunjang pola dasar pembangunan Nasional dan menggariskan apa yang menjadi tujuannya adalah penegasan cita-cita bangsa, seperti yang terkandung dalam Undang-Undang Dasar 1945.

Dalam mewujudkan pembangunan perhubungan diarahkan untuk lebih mempelancar arus barang dan jasa, serta usaha meningkatan mobilitas manusia.
Dimana arus perhubungan tersebut akan mempercepat pencapaian sasaran pembangunan, serta memperkokoh persatuan dan kesatuan bangsa dan kesatuan bangsa dalam meningkatkan ketahanan Nasional dan perwujudan wawasan nusantara, khususnya peranan PT. Kereta Api (Persero).

Kepercayaan konsumen atau pelanggan (Sugara \& Dewantara, 2017) pada dasarnya merupakan bentuk dukungan konsumen terhadap upaya yang dilakukan untuk mendapatkan segala sesuatu yang diinginkan, melalui kepercayaan seorang konsumen akan memberikan dukungan terkait dengan keputusan pembelian yang akan ditetapkan

Sesuai dengan pembangunan nasional seperti yang ditetapkan dalam Garis-Garis Besar Haluan Negara (GBHN), maka tujuan umum dari perhubungan yang lebih luas serta ditujukan untuk makin meningkatkan kemampuan angkutan dan untuk meningkatkan mutu pelayanan kereta api agar berfungsi sebagai angkutan umum yang murah, tertib, aman dan cepat.

Sementara dewasa ini PT. Kereta Api (Persero) sering menjadi sorotan pers yang lekat memberitakan berbagai tragedi kecelakaan kereta api. Sehingga ada beberapa pihak yang mempertanyakan siapa yang salah dan patut mempertanggung jawabkannya.

Kecelakaan ini tidak hanya terjadi pada beberapa negara maju saja, akan tetapi juga terjadi pada beberapa negara berkembang. Sebagai contoh Tragedi Bintaro, merupakan salah satu peristiwa kecelakaan kereta api yang sangat menakutkan dan tidak akan lupa dalarn ingatan bagi sejarah perkeretaapian, dan masyarakat Indonesia khususnya.

Berdasarkan penelitian oleh(Puspa Wildyaksanjani \& Dadang Sugiana, 2018)Strategi Customer Relationship Management (CRM) yang dilakukan PT Angkasa Pura II (Persero) di Bandara Internasional Husein Sastranegara Bandung 


\section{EKOMBIS Sains}

adalah dengan memberikan pelayanan prima kepada mitra usaha dan yang membedakan Bandara Internasional Husein Sastranegara Bandung dengan bandara lain di Indonesia adalah adanya program inovasi seperti lucky drawdan piagam penghargaan. Persepsi mitra usaha pada strategi Customer Relationship Management(CRM) yang dilakukan PT Angkasa Pura II (Persero) di Bandara Internasional Husein Sastranegara Bandung cukup beragam mulai dari persepsi yang bersifat positif ataupun negatif. Namun secara garis besar persepsi pelanggan lebih kepada masukan atau kritikan agar PT Angkasa Pura II (Persero) meningkatkan kualitas pelayanannya di Bandara Internasional Husein Sastranegara Bandung.

Penelitian selanjutnya (Hakim \& Idris, 2017) Hasil analisis menunjukkan bahwa kualitas pelayanan berpengaruh positif dan signifikan terhadap kepercayaan konsumen pada konsumen Go-Ride di Kota Bandung. Hal ini berdasarkan pada pengujian hipotesis dalam analisis Amos yang menghasilkan nilai Estimate sebesar 0,435 dan C.R sebesar 4,587 yang memenuhi syarat yaitu > 1,96 dengan nilai $\mathrm{p}$ sebesar yang memenuhi syarat yaitu $<0,05$

Provinsi lampung sebagai pintu gerbang transportasi antara pulau jawa dan sumatera. Provinsi lampung dengan ibu kota Tanjung Karang ini, dalam bidang tranportasi kereta api merupakan salah satu alat tranportasi yang ada di daerah tersebut. Kereta api yang berhubungan antara kota Palembang (Sumatera Selatan) dengan Tanjung Karang ini juga menghubungkan kota - kota kecil yang dilintasi kereta api seperti Prabumulih, Baturaja, Martapura, dan Kotabumi.

Terlepas dari kereta api sebagai fasilitas penunjang operasional kerja PT. Kereta Api (Persero), sumber daya manusia atau pengelolanya juga sangat menentukan keberhasilan yang tidak hanya dipandang dari keuntungan material saja tetapi juga dari berbagai sudut pandang atau pendapat. Hal yang dimaksud adalah opini masyarakat yang dapat membentuk citra positif atau negatif terhadap PT. Kereta Api (Persero). Salah satu faktor yang membentuk citra tersebut adalah tergantung pada sejauh mana pelayanan yang diberikan kepada pengguna jasa tersebut.

Untuk mendukung terealisasikannya pelayanan informasi dengan cara memantaunya merupakan menjadi bagian dari tugas Customer Relations. Customer Relations merupakan kegiatan pelayanan yang dilakukan PT. Kereta Api, yang ditujukan pada publik luar atau publik eksternal sebagai sasararmya. Dalam hal ini Customer Relations harus benar-benar dilakukan oleh karyawan melalui pelayanan informasi yang jelas, lengkap terhadap para calon pengguna jasa, pelayanan yang juga termasuk didalamnya adalah mengatur dan memelihara hubungan dengan para pelanggan sehingga hubungan tersebut selalu berada dalam keharmonisan yaitu atas dasar saling pengertian dan saling menghormati kepentingan bersama. Selanjutnya masyarakat atau publik eksternal akan memberikan berbagai pendapat atau opini terhadap pelayanan yang diberikan PT. Kereta Api (Persero).

Opini yang dinilai sebagai jawaban yang diucapkan oleh individu terhadap suatu rangsang atau situasi yang mengemukakan beberapa pertanyaan yang dipermasalahkannya. Opini merupakan pemyataan yang diucapkan atau berupa tulisan dan selanjutnya akan membentuk sikap. Dimana sikap adalah tendensi untuk memberikan reaksi yang positif atau yang menguntungkan, sikap negatif atau tidak menguntungkan terhadap orang-orang, objek atau situasi-situasi tertentu. Karena sikap merupakan suatu tendensi atau kecendrungan terhadap sesuatu untuk memberi reaksi yang bersifat emosional dalam arah tertentu.

Maka dari opini itu jika terbentuk opini yang baik atau favourable akan dapat menumbuhkan kepercayaan pengguna jasa Kereta Api Express, dengan demikian 


\section{EKOMBIS Sains}

Customer Relations sebagai pihak intern sangat berpengaruh didalamnya. Hal ini karena customer relations merupakan bagian dari kegiatan Hubungan Masyarakat (HUMAS), atau sering disebut Publik Relations (PR), HUMAS menurut Edwin Emercy, Phillip H. Ault, serta Warren K, bahwa humas memiliki fungsi sebagai upaya yang terencana untuk mempengaruhi dan membina opini yang menyenangkan melalui penampilan yang dapat diterima(Effendy, 2006). Menurut Canfield, mengemukakan fungsi humas adalah :

1. It should serve the public's interest. (mengabdi kepada kepentingan publik)

2. Maintain good communications (memelihara komunikasi yang baik)

3. Strees good morals and manners (menitikberatkan moral danperilaku yang baik).

Untuk mengetahui seberapa jauh pengaruh yang ditimbulkan oleh Customer Relations terhadap kepercayaan pengguna jasa Kereta Api Express pada PT. Kereta Api (Persero). Sehingga dalam karya ini diberikan judul adalah : "Analisis Customer Relation Dengan Kepercayaan Pengguna Jasa Kereta Api Express Pada PT. Kereta Api Indonesia (Persero) di Bandar Lampung.

\section{METODE PENELITIAN}

Jenis penelitian ini menggunakan kuantitatif deskriptif dengan teknik analisis menggunakan uji validasi product moment, pengujian hipotesis menggunakan uji t. Metode pengumpulan data yang menggunakan jenis data primer dan data skunder dengan teknik pengumpulan data menggunakan observasi, wawancara, angket. dan telaah kepustakaan. Jumlah populasi dalam penelitian ini adalah sejumlah 612 orang/responden. Jumlah tersebut adalah jumlah keseluruhan penumpang kereta api untuk pemberangkatan setiap harinya pada Kereta
Api Express, yaitu terhitung dari jumlah bangku atau tempat duduk yang tersedia. Diketahui bahwa setiap pemberangkatan, kereta api tersebut terdapat 7 gerbong. Dari 7 gerbong terdiri dari 1 gerbong adalah lokomotif, dan 6 gerbong khusus penumpang kereta api untuk pemberangkatan setiap harinya pada Kereta Api Express, yaitu terhitung dari jumlah bangku atau tempat duduk yang tersedia. Kapasitas tempat duduk setiap gerbongnya berjumlah 102 penumpang atau secara keseluruhan berjumlah 612 orang. Besarnya sampel dalam penelitian ini adalah sebesar $10 \%$ dari seluruh jumlah populasi. Hal ini sesuai dengan pendapat Suharsimi Arikunto, bahwa sebesar 10\%-15\% dari seluruh jumlah populasi yang ada dapat menjadi sampel. Sampel dalam penelitian ini adalah sebanyak 60 orang.

Uji validitas dalam penelitian ini menggunakan korelasi product moment. Persamaannya menurut DR Sudjana sebagai berikut :

$$
r x y=\frac{n \cdot \sum X Y-\left(\sum X\right) \cdot\left(\sum Y\right)}{\sqrt{\left[n \cdot \sum X^{2}-\left(\sum X\right)^{2}\left[n \cdot \sum Y^{2}-\left(\sum Y\right)^{2}\right]\right.}}
$$

Keterangan :

rxy $=$ Koefisien korelasi product moment

$r \quad=$ Korelasi

$\Sigma \quad=$ Jumlah

$\mathrm{n} \quad=$ Sampel

$\mathrm{x}=$ Hasil dari skor angket Variabel

bebas

$\mathrm{y}=$ Hasil dari skor angket Variabel terikat

xy $=$ Hasil perkalian Variabel bebas dengan Variabel terikat

$\mathrm{x}^{2}=$ Hasil perkalian kuadrat variabel bebas

$\mathrm{y}^{2+}=$ Hasil perkalian kuadrat variabel terikat

Dari perhitungan diatas, kemudian akan dikonsultasikan kepada skala interprestasi nilai "Y" untuk dapat mengetahui berapa besarnya hubungan antara Variabel bebas 


\section{EKOMBIS Sains}

(x) dengan Variabel terikat (y) menurut Arikunto (2006 : 209) adalah :

Tabel 1. Skala interprestasi nilai "Y"

\begin{tabular}{|c|c|c|}
\hline $0,810-1000$ & Kategori & Tinggi \\
$0,610-0,800$ & Kategori & Cukup \\
$0,410-0,600$ & Kategori & Agak rendah \\
$0,210-0,400$ & Kategori & Rendah \\
$0,001-0,200$ & Kategori & Sangat rendah \\
\hline
\end{tabular}

\section{HASIL DAN PEMBAHASAN}

Berdasarkan hasil penelitian tentang Analisis Customer Relation Dengan Kepercayaan Pengguna Jasa Kereta Api Express Pada PT. Kereta Api Indonesia (Persero) Di Bandar Lampung

\section{Uji Validitas}

\section{Analisis Kualitatif}

Untuk mengetahui pengaruh customer relation dengan kepercayaan pengguna jasa kereta api express, maka digunakan alat analisis kualitatif dan kuantitatif. Pada analisis kualitatif ini penulis akan menganalisis berdasarkan teori-teori yang berkaitan dengan customer relation dengan kepercayaan pengguna jasa kereta api express. Dengan didasarkan atas teori tersebut, maka langkah selanjutnya adalah membuat daftar pertanyaan/kuisioner yang akan diseberkan kepada 27 orang sebagai responden penelitian.

Setiap alternatif jawaban yang diberikan tersebut akan diberi skor dengan ketentuan sebagai berikut :
a. Apabila alternatif jawaban A, maka diberi skor 3 .
b. Apabila alternatif jawaban B, maka diberi skor 2 .
c. Apabila alternatif jawaban $\mathrm{C}$, diberi skor 1.

Dengan demikian jumlah skor maksimal dan minimal dari 10 item pertanyaan adalah 10 sampai dengan 30, yang dibagi dalam kategori :

Sangat baik/Tinggi dengan skor antara 23 sampai dengan 30

Baik/Sedang dengan skor antara 16 sampai dengan 22 Kurang/Rendah dengan skor antara 10 sampai dengan 15

Berdasarkan hasil rekapitulasi jawaban kuisioner dari 27 orang responden (lampiran 6) diperoleh hasil sebagai berikut : 17 orang responden $(62,96 \%)$ menjawab customer relation sangat baik, 7 orang responden $(25,93 \%)$ menjawab customer relation baik dan 3 orang responden $(11,11$ $\%$ ) menjawab customer relation kurang baik.

Sedangkan yang berkaitan dengan kepercayaan pengguna jasa kereta api express diperoleh hasil : 16 orang responden $(59,26 \%)$ menjawab kepercayaan pengguna jasa kereta api express sangat meningkat, 3 orang responden $(11,11 \%)$ menjawab kepercayaan pengguna jasa kereta api express meningkat dan 8 orang responden $(29,63 \%)$ menjawab kepercayaan pengguna jasa kereta api express menurun.

Dasi hasil jawaban kuisioner tersebut di atas akan direkapitulasi pada tabel III sebagaimana berikut ini :

Tabel 2. Rekapitulasi Jawaban Hasil Kuisioner dari 27 orang Responden pada PT. Kereta Api Indonesia (Persero)

\begin{tabular}{|c|c|c|c|}
\hline \multirow[b]{2}{*}{ Keterangan } & \multicolumn{3}{|c|}{ Kriteria } \\
\hline & $\begin{array}{c}\text { Sangat } \\
\text { baik }\end{array}$ & Baik & Kurang \\
\hline $\begin{array}{l}\text { Customer } \\
\text { Relation }\end{array}$ & $\begin{array}{l}17 \\
(62,96 \% \\
)\end{array}$ & $\begin{array}{l}7 \\
(25,93 \% \\
)\end{array}$ & $\begin{array}{l}3 \\
(11,11 \% \\
)\end{array}$ \\
\hline $\begin{array}{l}\text { Kepercayaa } \\
\text { n Pengguna } \\
\text { Jasa }\end{array}$ & $\begin{array}{l}16 \\
(59,26 \%\end{array}$ & $\begin{array}{l}3 \\
(11,11 \%\end{array}$ & $\begin{array}{l}8 \\
(29,63 \%\end{array}$ \\
\hline Rata-rata & $61,11 \%$ & $18,52 \%$ & $20,37 \%$ \\
\hline
\end{tabular}

Sumber : Data diolah

Dari tabel 3 tersebut di atas terlihat bahwa rata-rata jawaban responden dari kuisioner yang berkaitan dengan customer relation maupun kepercayaan penggunaan jasa diperoleh hasil : rata-rata $61,11 \%$ responden menyatakan sangat baik, 18,52\% 


\section{EKOMBIS Sains}

menyatakan baik dan 20,37 \% menyatakan kurang.

Berdasarkan analisis kualitatif tersebut, maka dapat disimpulkan bahwa "Ada Pengaruh positif dari customer relation terhadap kepercayaan pengguna jasa kereta api express pada PT. Kereta Api Indonesia (Persero) di Bandar Lampung”.

\section{Analisis Kuantitatif}

Setelah dianalisis menggunakan analisis kualitatif, maka penulis juga akan menganalisis dengan menggunakan data kuantitatif. Data kuantitatif ini diperoleh dari mentabulasikan hasil kuesioner yang penulis sebarkan kepada 27 orang responden dalam bentuk angka-angka sesuai dengan skor jawaban yang telah dijelaskan pada bab sebelumnya.

Dari hasil tabulasi dalam bentuk angka-angka tersebut sebagaimana terlampir pada lampiran 3 dan 4, kemudian penulis olah melalui rumus statistik yaitu Product Moment, sehingga dapat dilihat hubungan antara variabel customer relation (X), maupun yang berhubungan pengguna jasa kereta api (Y).

Berdasarkan rekapitulasi hasil kuesioner (lampiran 6) diperoleh :

$$
\begin{aligned}
\mathrm{N} & =27 \\
\sum \mathrm{X}^{2} & =17.310 \\
\sum \mathrm{X} & =668 \\
\sum \mathrm{Y}^{2} & =16.487 \\
\sum \mathrm{Y} & =647 \\
\sum \mathrm{XY} & =16.851
\end{aligned}
$$

Selanjutnya dari angka-angka tersebut di atas, penulis menggunakan rumus product moment dengan hasil sebagai berikut :

$$
\frac{r_{y x}=}{N \cdot \sum X Y-\left(\sum X\right)\left(\sum Y\right)} \frac{\sqrt{\left\{N \cdot \sum X^{2}-\left(\sum X\right)^{2} \cdot\left(N \cdot \sum Y^{2}-\left(\sum Y\right)^{2}\right\}\right.}}{}
$$

$$
\begin{gathered}
r_{y x}= \\
\frac{27 .(16.851)-(668)(647)}{\sqrt{\left\{27.17 .310-(668)^{2} .27 .16 .487-(647)^{2}\right\}}} \\
r_{y x}= \\
\frac{454.977-432.196}{\sqrt{\{(467.370-446.224) \cdot(445.149-418.609)\}}} \\
\quad=\frac{22.781}{\sqrt{(21.146) \cdot(26.540)}} \\
r_{y x}=\frac{22.781}{\sqrt{561.514 .840}} \\
r_{y x} \\
r_{y x}=\frac{22.781}{23.689,97341} \\
r_{y x}=\mathbf{0 , 9 6 2}
\end{gathered}
$$

Setelah diketahui $r_{\text {xyhitung }}=0,962$, maka setelah dibandingan dengan nilai $r_{\text {xytabel }}$ product moment pada $\mathrm{n}=27$ pada taraf signifikan $5 \%=0,381$ maupun pada taraf signifikan $1 \%=0,487$ perbandingan tersebut menunjukkan $r$ hitung = $0,962>r_{\text {table }}$ taraf signifikan $5 \%=0,381$ dan $1 \%=0,487$. Kemudian dibandingkan pula dengan standar pengukuran korelasi ternyata $r_{x y h i t u n g}=0,962$ terletak antara 0,810 - 1,000 dengan kriteria sangat tinggi.

Berdasarkan hasil perhitungan tersebut di atas, maka penulis menyimpulkan bahwa hipotesis yang menyatakan bahwa "Ada pengaruh positif dari customer relation dengan pengguna jasa kereta api express pada PT. Kereta Api Indonesia (Persero) di Bandar Lampung", terbukti kebenarannya

Kadar Prosentase

Untuk mengetahui kadar prosentase pengaruh customer relation dengan pengguna jasa kereta api express pada PT. Kereta Api Indonesia (Persero), maka penulis akan menggunakan rumus Koefisien Penentu (KP) sebagai berikut :

$\mathrm{KD}=r^{2} \times 100 \%$

Nilai $r_{\text {hitung }}=\mathbf{0 , 9 6}$ yang diperoleh dari hasil perhitungan sebelumnya, maka 


\section{EKOMBIS Sains}

dapat dihitung nilai kadar prosentasenya sebagai berikut :

$$
\begin{aligned}
\mathrm{KD} & =r^{2} \times 100 \% \\
\mathrm{KD} & =(0,96)^{2} \times 100 \% \\
\mathrm{KD} & =0,92 \times 100 \% \\
\mathrm{KP} & =92,5 \%
\end{aligned}
$$

Hasil perhitungan Koefisien Penentu tersebut menunjukkan bahwa 92,5\% ada pengaruh customer relation dengan pengguna jasa kereta api express, sementara faktor lain hanya $7,46 \%$.

\section{Uji Hipotesis}

Untuk mengetahui kebenaran hipotesis yang telah penulis kemukakan, maka berikut ini akan penulis sajikan uji hipotesis. Uji hipotesis ini ditujukan untuk mengukur tingkat kevalidan dari hasil perhitungan sebelumnya. Untuk menguji hipotesis yang telah penulis kemukakan, maka dipergunakan rumus $t$ test sebagai

$$
\text { berikut: } \begin{aligned}
t & =\frac{r \sqrt{N-2}}{\sqrt{1-r^{2}}} \\
t & =\frac{0,962 \sqrt{27-2}}{\sqrt{1-(0,962)^{2}}} \\
t & =\frac{0,962 \sqrt{25}}{\sqrt{1-0,925444}} \\
t & =\frac{0,962 \cdot 5}{\sqrt{0,074556}} \\
t & =\frac{4,81}{0,2730} \\
t & =\mathbf{1 7 , 6 2}
\end{aligned}
$$

Nilai $t_{\text {hitung }}$ diperoleh sebesar $=17,62$ pada $\mathrm{N}=27$. setelah nilai tersebut dibandingkan dengan nilai $t$ tabel dengan menggunakan derajat kebebasan $(d b) \mathrm{N}-2$, tingkat signifikan $(\alpha=5 \%)$ diperoleh hasil $t$ hitung lebih besar daripada $\quad t_{\text {tabel }}$ yaitu $: t_{\text {hitung }}=17,62>\mathrm{t}_{0,05}(\mathrm{~N}-2)=1,708$. Dengan demikian dapat disimpulkan bahwa, hipotesis yang sebelumnya penulis ajukan yaitu "Ada pengaruh positif dari customer relation dengan pengguna jasa kereta api express pada PT. Kereta Api
Indonesia (Persero) di Bandar Lampung”, dapat diterima

\section{KESIMPULAN}

Berdasarkan hasil penelitian menunjukan bahwa nilai $\mathrm{t}$ hitung diperoleh sebesar $=17,62$ pada $N=27$. Setelah nilai tersebut dibandingkan dengan nilai $t$ tabel dengan menggunakan derajat kebebasan (db) $\quad 95 \%(\alpha=5 \%)$ diperoleh hasil $t$ hitung lebih besar daripada $\mathrm{t}$ tabel yaitu : $\mathrm{t}$ hitung $\quad=17,62>\mathrm{t} \mathrm{0,05}(\mathrm{n}-2)=1,708$. Dengan demikian dapat disimpulkan bahwa, hipotesis yang sebelumnya penulis ajukan yaitu "Ada pengaruh positif dari customer relation dengan kepercayaan pengguna jasa kereta api express pada PT. Kereta Api Indonesia (Persero) di Bandar Lampung.

\section{DAFTAR PUSTAKA}

Dewa, B. P., Setyohadi, D. B., Studi, P., Teknik, M., Pascasarjana, P., \& Jaya, U. A. (2017). ANALISIS DAMPAK FAKTOR CUSTOMER RELATIONSHIP MANAGEMENT DALAM MELIHAT TINGKAT KEPUASAN DAN LOYALITAS. 14(01), 33-38.

Effendy, O. U. (2016). Ilmu Komunikasi, Teori dan Praktek. Rosdakarya.

Hakim, R. H., \& Idris. (2017). Analisis Faktor-Faktor yang Mempengaruhi Kepercayaan Konsumen Serta Implikasinya Terhadap Keputusan Pembelian ( Studi kasus pada Go-Ride di Kota Bandung ). Diponegoro Journal of Management, 6(1), 1-11.

Jain, Rajnish. 2010. Jurnal Internasional, CRM pada ritel sebuah perspektif

lingkungan. International Journal of 


\section{EKOMBIS Sains}

Management. Vol. 1, No.1

Janelle Drarlow \& Dianna Maul Artikel: Emotional value: Creating Strong Brand with Your Custumer

Kanaidi \& Kurniawan, Ari. 2011. Analisis Customer Relationship Management(CRM) pada SBU ADMAIL. Skripsi.

Kotler, Philip \& Keller, Kevin Lane, 2008. Marketing Management. Edisi kedua

belas jilid 1. PT. Macanan Jaya Cemerlang. Jakarta.

Kotler, Philip. 2003. Marketing Insights From a to Z. Erlangga. Jakarta

Puspa Wildyaksanjani, J., \& Dadang Sugiana, dan. (2018). Strategi Customer Relationship Management
(CRM) PT Angkasa Pura II (Persero). Jurnal Kajian Komunikasi, 6(1), 1023.

Sugara, A., \& Dewantara, R. Y. (2017). Analysis of Trust and Satisfaction with the Use of the Online Buying and Selling Transaction System (Analisis Kepercayaan Dan Kepuasan Terhadap Penggunaan Sistem Transaksi Jual Beli Online). 52(1), 8-15.

Sugiono. 2008. Memahami Penelitian Kualitatif. CV Alfabeta. Hlm. 89. Bandung:

Sugiono. 2011. Metodologi Penelitian Kuantitatif, Kualitatif, dan RnD. Alfabeta.Hlm. 139. Bandung. 